University of Nebraska - Lincoln

DigitalCommons@University of Nebraska - Lincoln

Sociology Department, Faculty Publications

Sociology, Department of

10-2006

\title{
Impact of family abuse on running away, deviance, and street victimization among homeless rural and urban youth
}

\author{
Lisa E. Thrane \\ Wichita State University, lisa.thrane@wichita.edu \\ Dan R. Hoyt \\ University of Nebraska-Lincoln, dhoyt2@unl.edu \\ Les B. Whitbeck \\ University of Nebraska-Lincoln, Iwhitbeck2@unl.edu \\ Kevin A. Yoder \\ University of North Texas
}

Follow this and additional works at: https://digitalcommons.unl.edu/sociologyfacpub

Thrane, Lisa E.; Hoyt, Dan R.; Whitbeck, Les B.; and Yoder, Kevin A., "Impact of family abuse on running away, deviance, and street victimization among homeless rural and urban youth" (2006). Sociology Department, Faculty Publications. 208.

https://digitalcommons.unl.edu/sociologyfacpub/208

This Article is brought to you for free and open access by the Sociology, Department of at DigitalCommons@University of Nebraska - Lincoln. It has been accepted for inclusion in Sociology Department, Faculty Publications by an authorized administrator of DigitalCommons@University of Nebraska - Lincoln. 


\title{
Impact of family abuse on running away, deviance, and street victimization among homeless rural and urban youth
}

\author{
Lisa E. Thrane, ${ }^{1}$ Danny R. Hoyt ${ }^{2}$ Les B. Whitbeck, ${ }^{2}$ and Kevin A. Yoder ${ }^{3}$ \\ 1. Department of Sociology, Wichita State University, Wichita, KS, USA \\ 2. Department of Sociology, University of Nebraska-Lincoln, Lincoln, NE, USA \\ 3. Department of Sociology, University of North Texas, Denton, TX, USA \\ Corresponding author - L. E. Thrane, Wichita State University, \\ 401 Lindquist Hall, Box 25, Wichita, KS 67260, USA.
}

\begin{abstract}
Problem - Various demographic and familial risk factors have been linked to runaway behavior. To date, there has not been a systematic investigation of the impact of size of community on runaway behavior. This study will compare runaways from smaller cities and rural areas to their urban counterparts.

Methods - A convenience sample of 602 adolescents was interviewed between 1995 and August of 1996 in Missouri, Iowa, Nebraska, and Kansas, USA. Multiple regression was used to examine the association between gender, neglect, sexual abuse, physical abuse, geographic and family structure change, and community size of first runaway to predict age at first runaway, deviant subsistence strategies, and street victimization.

Results - Findings indicate that adolescents exposed to neglect $(\beta=-.20)$ and sexual abuse $(\beta=-.16)$ ran away sooner and were more likely to be victimized on the street. Rural adolescents who experienced higher levels of physical abuse relied more heavily on deviant subsistence strategies $(\beta=.15)$ and remained in abusive homes longer $(\beta=.15)$ than their similarly situated urban counterparts.

Conclusions - Rural youth who have been subjected to elevated levels of familial abuse are at greater risk of deviant subsistence strategies, which increase the likelihood of street victimization.
\end{abstract}

Keywords: abuse, neglect, runaway, deviance, victimization, rural 


\section{Introduction}

In the United States, the annual number of adolescent runaways has been estimated between 500,000 and 1.5 million (Committee on Labor, 1990; Finkelhor, Hotaling, \& Sedlak, 1990; Hammer, Finkelhor, \& Sedlak, 2002). Homeless and runaway adolescents report running from sexual and physical abuse and neglect (Janus, Burgess, \& McCormack, 1987; Powers, Eckenrode, \& Jaklitsch, 1990; Stiffman, 1989; Whitbeck \& Hoyt, 1999), and studies have linked childhood victimization to delinquency (Herrera \& McCloskey, 2001; Kaufman \& Spatz Widom, 1999; Zingraff, Leiter, Myers, \& Johnson, 1993). Maltreatment also is associated with deviant subsistence strategies (Hagan \& McCarthy, 1997; McCormack, Burgess, \& Gaccione, 1986; Whitbeck \& Simons, 1990) and street victimization (Janus, Archambault, Brown, \& Welsh, 1995; Simons \& Whitbeck, 1991; Tyler, Hoyt, Whitbeck, \& Cauce, 2001; Whitbeck, Hoyt, \& Ackley, 1997) among homeless and runaway youth. Adolescents' reliance on the street economy increases their exposure to motivated offenders and further victimization (Lauritsen, Sampson, \& Laub, 1991).

To date, there has not been a systematic investigation of the impact of size of community on runaway behavior. Little is known about youth who run away in smaller cities and rural areas, and few comparisons have been made to their urban counterparts. Specifically, this paper will evaluate family factors and community size differences that contribute to running away, deviant subsistence strategies, and street victimization. It will also investigate interaction between community size and family and street variables. Small Midwestern communities may have fewer safety nets available for young people contemplating running away from abusive homes. As a result, rural youth may be more damaged and chart a more delinquent post-runaway trajectory.

\section{Literature review}

\section{Running from dysfunctional families}

Dysfunctional and disorganized homes set the stage for running away at a relatively young age (Tyler et al., 2001). Runaways were more likely than non-runaways to report their parents did not care about them (Whitbeck, Hoyt, \& Ackley, 1997). Familial physical and sexual abuse is not uncommon (Hagan \& McCarthy, 1997; Janus et al., 1987; Kufeldt \& Nimmo, 1987; Whitbeck \& Hoyt, 1999; Whitbeck \& Simons, 1990). For example, in one study, nearly $75 \%$ of male runaways were physically abused, while $38 \%$ were survivors of sexual abuse (Janus et al., 1987).

\section{Familial effects on deviance}

Maladaptive familial relations like abuse and neglect could have the net effect of escalating the use of deviant street survival strategies (Hagan \& McCarthy, 1997; Simons \& Whitbeck, 1991; Whitbeck \& Hoyt, 1999). While physically abused youth were more likely to commit a violent offense (Maxfield \& Spatz Widom, 1996), physical abuse increased the risk of runaway behavior which then promoted deviant street behavior (Simons \& Whitbeck, 1991). 


\section{Risk factors for street victimization}

Physical and sexual street victimization has been well documented (Hagan \& McCarthy, 1997; Kipke, Simon, Montgomery, Unger, \& Iverson, 1997; Tyler et al., 2001; Whitbeck \& Hoyt, 1999). Deviant subsistence strategies have been shown to increase the risk of exploitation and victimization (Baron, 2003; Hagan \& McCarthy, 1997; Lauritsen et al., 1991; Whitbeck \& Hoyt, 1999). In a study of Los Angeles' homeless adolescents, nearly $75 \%$ witnessed physical attacks whereas $50 \%$ had been physically threatened (Kipke et al., 1997). Abuse has been linked to victimization while on the street (Janus et al., 1995; Lee \& Schreck, 2005; Tyler et al., 2001; Whitbeck \& Hoyt, 1999; Whitbeck, Hoyt, \& Ackley, 1997). For instance, childhood sexual abuse led to risky behavior (e.g., deviance subsistence strategies, deviant peers, and survival sex), which influenced sexual victimization after running away (Tyler et al., 2001). Homeless and runaway youth may have fewer resources to prevent street victimization (Hoyt, Ryan, \& Cauce, 1999), which could increase their vulnerability to repeated incidents (Johnson, Bowers, \& Hirschfield, 1997).

\section{Community effects}

Since the 1980s, economic decline in agriculture and rural America is the well-established pattern (Drabenstott \& Gibson, 1988), which has left many rural communities without needed human capital and resources to rebuild the economic base (Hoyt, Conger, Gaffney Valde, \& Weihs, 1997). In a survey of Missouri's child welfare agency, inadequate resources to fulfill one's job responsibilities were significantly associated with more rural areas (Landsman, 2002). The changes in small rural places are likely to remove access to formal opportunities for youth services as well as federal and state funds for social welfare programs to aid runaways. Since little research has focused on community size, this study aims to fill a void in the literature by exploring the ramifications of family risk factors among runaways from rural and urban communities.

\section{Theory}

Nye's (1979) exchange perspective provides the framework for analyzing how resources affect the choices of homeless and runaway adolescents. Youth consider the numerous costs and benefits of running away and take the action that brings the greatest reward at the least expense. Young people may yearn for independence from the family of origin. In this case, running away increases rewards. On the other hand, adolescents can reach a point where family disorganization or dysfunction is more deleterious than the costs of leaving; so they run to decrease costs (Nye, 1980).

\section{Hypotheses}

The review of the homeless and runaway literature indicates that physical and sexual abuse and neglect are positively associated with running away (Janus et al., 1987; Kufeldt \& Nimmo, 1987; Whitbeck \& Simons, 1990; Whitbeck \& Hoyt, 1999). Hypothesis 1: We predicted that youth from 
dysfunctional families (e.g., neglect and abuse) will run away earlier than youth with stable family relations. Hypothesis 2: We hypothesized that physical abuse and age at first runaway will be more strongly positively correlated for rural than urban youth because rural communities may have fewer programs and resources available to aid runaway youth. In this case, abused rural youth may delay running away because there are not social welfare programs in place to provide needed resources.

It has been shown that maladaptive familial relations influence street survival strategies (Baron, 2003; Hagan \& McCarthy, 1997; Whitbeck \& Hoyt, 1999). Hypothesis 3: We predicted that dysfunctional family patterns will increase the use of street deviance. In rural communities, difficult family relations could alienate young people from valuable social networks making them even more vulnerable when they run away. Hypothesis 4: We hypothesized that rural runaways who have been exposed to various risk factors (e.g., family abuse and neglect) will rely on deviant subsistence strategies more so than urban youth who have had similar life experiences.

Street life exposes runaway and homeless youth to criminal opportunity, trauma, and victimization (Whitbeck \& Hoyt, 1999). Youth who run away from dysfunctional families may be more damaged as a result and more vulnerable to street predators. Hypothesis 5: We predicted that maladaptive family relations (e.g., abuse and neglect) will increase the rate of street victimization. In addition, studies have shown that the use of deviant survival strategies increases the risk of being physically and sexually victimized after running away (Baron, 2003; Hagan \& McCarthy, 1997; Tyler et al., 2001). Hypothesis 6: We predicted that adolescents' reliance on deviant survival strategies would increase their risk of being victimized on the street.

\section{Methods}

\section{Sample}

A convenience sample of 602 adolescents was interviewed between 1995 and August of 1996 in Missouri, Iowa, Nebraska, and Kansas (Whitbeck \& Hoyt, 1999). Six agencies with existing street outreach programs provided expertise and access to the studied population. Agency staff was trained to conduct interviews with homeless and runaway youth.

Age ranged from 12 to 22 years. The average age was 16 years for females and 16.6 years for males. Females represented $60 \%$ of the sample. The sample was composed of Whites (61\%), African Americans (24\%), Hispanic and American Indians (3\%; 3\%, respectively), and other racial and ethnic groups were reported by $9 \%$ of adolescents. Nearly half $(49 \%)$ of adolescents reported spending most of the week prior to the interview in a shelter, $23 \%$ stayed with friends, $14 \%$ resided with family, and $14 \%$ reported various other arrangements.

\section{Procedures}

This research design improved on previous studies by sampling multiple sites with widely varying populations (14,000-339,000). Within smaller cities in Iowa (Cedar Rapids, Mason City, and Davenport) and Nebraska (Scottsbluff), smaller shelters were sampled. Respondents received \$15 for their participation. The project was approved by the Iowa State University Institutional Board. Verbal informed consent was obtained from adolescents. Their participation was voluntary and could be terminated at any time. Interviewers were mandated reporters of child maltreatment. 
The overall response rate was $93 \%$, but ranged from $71 \%$ to $100 \%$ depending on the agency. The response rate is (total number of interviews)/(total number of interviews + total number of refusals).

\section{Measures}

Outcome variables - There were three outcome measures. Age at first runaway was computed by subtracting the year that the adolescent ran away the first time from the year of birth. Deviant subsistence strategies was assessed with a checklist of 15 items. Respondents were asked to indicate whether they had relied upon various sexual and non-sexual means to get money, food, shelter, or drugs while on their own (Whitbeck \& Simons, 1990). The subscales were given equal weight in the scale with higher scores representative of greater use of deviant subsistence strategies. Individual item response categories were $0=$ "no" and $1=$ "yes." Cronbach's alpha was .81. Street victimization was computed as a sum of nine items that asked whether the young person had been robbed, beaten, sexually assaulted, threatened with a weapon, deprived of food for 24 hours, asked to steal, or sell drugs after running away (Whitbeck \& Simons, 1990). Response categories ranged from $0=$ "never" to $2=$ "twice or more." Physical and sexual victimization were equally weighted in the scale. Cronbach's alpha was .80. To induce normality, a natural logarithm transformation was applied to the deviant subsistence strategies and street victimization variables. The transformed variables are used in the analysis.

Predictor variables - Family factor variables consisted of the following five variables. All variables that reflect familial abuse and neglect are indicators of abuse or neglect by adult caretakers prior to running away from home. Sexual abuse prior to first runaway was computed from two dichotomous items adapted from Whitbeck and Simons (1990). Adolescents who indicated that they had never been asked or forced to do something sexual by an adult caretaker prior to running away were assigned a value of 0 , while those who responded positively to at least 1 of the two items were coded as 1. Physical abuse prior to first runaway by an adult caretaker was the sum of seven dichotomous items (e.g., beaten up, threatened with a weapon) adapted from the conflict tactics scale (CTS; Straus \& Gelles, 1990). Response categories were $0=$ "no" and $1=$ "yes." Cronbach's alpha for the measure was .88. Neglect prior to first runaway was computed as a sum of two dichotomous measures (e.g., abandoned or deprived of basic necessities). Response categories were $0=$ "no" and $1=$ "yes." (Whitbeck \& Simons, 1990).

Yearly average geographic change prior to first runaway was the average number of times that the adolescent's family relocated before he/she ran away. Yearly average family structure change prior to first runaway was the yearly average of family composition change prior to running away the first time consisting of such things as divorce, remarriage, or death.

Community size of first runaway divided the sample into two groups based upon the community size adolescents reported that they had run away from the first time. Adapted from Hoyt et al. (1997), the community size of first runaway was operationalized as seven categories: "big city (greater than 100,000)," "suburb of a big city," "medium-sized city $(50,000-100,000)$, " "town or small city $(10,000$ $50,000)$, , "small town (2,500-10,000)," very small town (less than 2,500)," and "country/farm." Rural adolescents (coded 1) lived in a community of less than 2,500 or nearby on farms or in the country. Urban adolescents (coded 0) lived in small towns $(2,500-10,000)$ up to and including metropolitan areas of 100,000 or more. Gender was coded $0=$ "female" and $1=$ "male." A full description of the variables is available from the author upon request. 


\section{Data analysis}

First, the analysis plan involved a comparison of rural and urban groups to determine if they differed on the independent variables. Three separate linear regression models were estimated with SPSS 10.0. Gender, family, and community variables were entered in one block for each of the models: (1) age at first runaway, (2) deviant subsistence strategies, and (3) street victimization. Furthermore, the variable age at first runaway was added in the second model, and age at first runaway and deviant subsistence strategies were included in the third model. Interactions with community size of first runaway and family variables were tested. In the latter two models, interactions with community size of first runaway and street variables (e.g., deviant subsistence strategies and street victimization) were considered. For the final models, residual analysis was performed to verify that the model assumptions were being met.

\section{Results}

Rural youth comprised 7\% $(n=42)$ of the sample. Of rural youth, $76 \%$ were interviewed in a metropolitan shelter, compared to $93 \%$ of urban runaways. No statistically significant differences were detected when comparing the rural and urban groups. Means and standard deviations as well as the percentage of adolescents who reported each of the characteristics are noted in Table 1. Neglect was reported by $27 \%$ of urban youth compared to $24 \%$ of rural adolescents. Sexual abuse affected about one in five youth (19\% for urban; $17 \%$ for rural). Physical abuse was much more common. Of urban runaways, $83 \%$ reported physical abuse compared to $76 \%$ of their rural counterparts. About half reported at least one residential move (49\% of urban youth vs. $43 \%$ of rural youth) while over twothirds experienced family structure change (68\% vs. $64 \%$, respectively); overall the average number of these occurrences was less than one a year prior to running away. For example, the mean for rural adolescents was $.11(S D=.20)$. About half $(56 \%)$ of urban adolescents engaged in deviant subsistence strategies (45\% of rural youth). Street victimization was reported by nearly three of four adolescents (73\% of urban vs. $79 \%$ of rural).

Table 1. Test for equality of means and percentage of adolescents' reporting the characteristic

\begin{tabular}{|c|c|c|c|c|c|c|}
\hline \multirow[b]{2}{*}{ Variables } & \multicolumn{3}{|c|}{ Urban $(n=557)$} & \multicolumn{3}{|c|}{ Rural $(n=42)$} \\
\hline & Mean & $S D$ & $\%$ & Mean & $S D$ & $\%$ \\
\hline Male & $\mathrm{N} / \mathrm{A}$ & $\mathrm{N} / \mathrm{A}$ & 40 & $\mathrm{~N} / \mathrm{A}$ & $\mathrm{N} / \mathrm{A}$ & 43 \\
\hline Neglect ${ }^{\mathrm{a}}$ & .03 & .06 & 27 & .03 & .06 & 24 \\
\hline Sexual abuse ${ }^{a}$ & .03 & .07 & 19 & .02 & .05 & 17 \\
\hline Physical abuse ${ }^{a}$ & .24 & .18 & 83 & .20 & .15 & 76 \\
\hline Average yearly geographic change ${ }^{a}$ & .09 & .13 & 49 & .11 & .20 & 43 \\
\hline Average yearly family structure change ${ }^{a}$ & .12 & .14 & 68 & .11 & .12 & 64 \\
\hline Age at first runaway & 13.50 & 2.54 & $\mathrm{~N} / \mathrm{A}$ & 14.12 & 2.10 & $\mathrm{~N} / \mathrm{A}$ \\
\hline Deviant subsistence strategies ${ }^{a}$ & .12 & .14 & 56 & .08 & .13 & 45 \\
\hline Street victimization ${ }^{\mathrm{a}}$ & .28 & .13 & 73 & .24 & .25 & 79 \\
\hline
\end{tabular}

There were no statistically significant differences between the urban and rural groups. a. Scale mean 
Table 2. Regression models for age at first runaway, deviant subsistence strategies, and street victimization

\begin{tabular}{|c|c|c|c|c|c|c|}
\hline \multirow[b]{2}{*}{ Independent variable } & \multicolumn{2}{|c|}{$\begin{array}{l}\text { Model } 1 \\
\text { Age at first } \\
\text { runaway } \\
(n=583)\end{array}$} & \multicolumn{2}{|c|}{$\begin{array}{l}\text { Model } 2 \\
\text { Deviant } \\
\text { subsistence } \\
\text { strategies }(n=567)\end{array}$} & \multicolumn{2}{|c|}{$\begin{array}{l}\text { Model } 3 \\
\text { Street } \\
\text { victimization } \\
(n=566)\end{array}$} \\
\hline & $B$ & $\beta$ & $B$ & $\beta$ & $B$ & $\beta$ \\
\hline Gender ( 1 = male $)$ & $-.40^{*}$ & -.08 & $.09^{* *}$ & .30 & -.03 & -.06 \\
\hline Neglect & $-8.83^{* *}$ & -.20 & .18 & .07 & $.60^{* *}$ & .13 \\
\hline Sexual abuse & $-5.88^{* *}$ & -.16 & .06 & .03 & $.51^{* *}$ & .13 \\
\hline Physical abuse & -.79 & -.06 & .03 & .04 & .06 & .04 \\
\hline Geographic change & -.56 & -.03 & -.00 & -.01 & $-.20^{* *}$ & -.10 \\
\hline Family structure change & $-3.01^{* *}$ & -.17 & -.03 & -.03 & $.15^{*}$ & .08 \\
\hline Age at first runaway & - & - & -.00 & -.02 & -.00 & -.02 \\
\hline Deviant subsistence strategies & - & - & - & - & $.94^{* *}$ & .49 \\
\hline Physical abuse $\times$ community size & $5.70^{*}$ & .15 & $.33^{*}$ & .15 & -.37 & -.09 \\
\hline Geographic change $\times$ community size & -2.55 & -.06 & .12 & .05 & - & - \\
\hline Age at first runaway $\times$ community size & - & - & $-.03^{*}$ & -.77 & - & - \\
\hline Sexual abuse $\times$ community size & 1.95 & .01 & - & - & - & - \\
\hline Community size (1 = rural) & -.40 & -.04 & .30 & .55 & .09 & .08 \\
\hline Constant & 14.71 & & .09 & & .17 & \\
\hline$R^{2}$ & & .16 & & .13 & & .32 \\
\hline Adjusted $R^{2}$ & & .15 & & .11 & & .30 \\
\hline
\end{tabular}

Community size of first runaway is abbreviated to community size.

${ }^{*} p<.05 ;{ }^{* *} p<.01$

\section{Model 1}

The first model predicted age at first runaway. As shown in Table 2, females as compared to males $(\beta=-.08)$, those who where neglected by an adult caretaker $(\beta=-.20)$, or who were sexually abused $(\beta=-16)$ ran away earlier. The association of neglect and sexual abuse with age at first runaway was consistent with our first hypothesis. Family structure change also led to youth running away earlier $(\beta=-.17)$. However, geographic change was not related to age at first runaway.

The relationship between physical abuse and age at first runaway depends on the size of the community, which is indicated by a statistically significant interaction $(\beta=.15)$. The rate of physical abuse had little influence on urban youth's age at first runaway (see Figure 1). However, at higher rates of physical abuse, rural adolescents delayed running away nearly a year and a half compared to their urban counterparts consistent with our second hypothesis. This model explained $15 \%$ of the variation in age at first runaway.

\section{Model 2}

The second model explored the relationship between the use of deviant street subsistence strategies and various risk factors (Table 2). Males were more likely than females to use deviant subsistence strategies $(\beta=.30)$. Prior familial neglect and sexual abuse did not predict adolescents' use of street deviance. Moreover, geographic change, change in family structure, and age at first runaway had no 


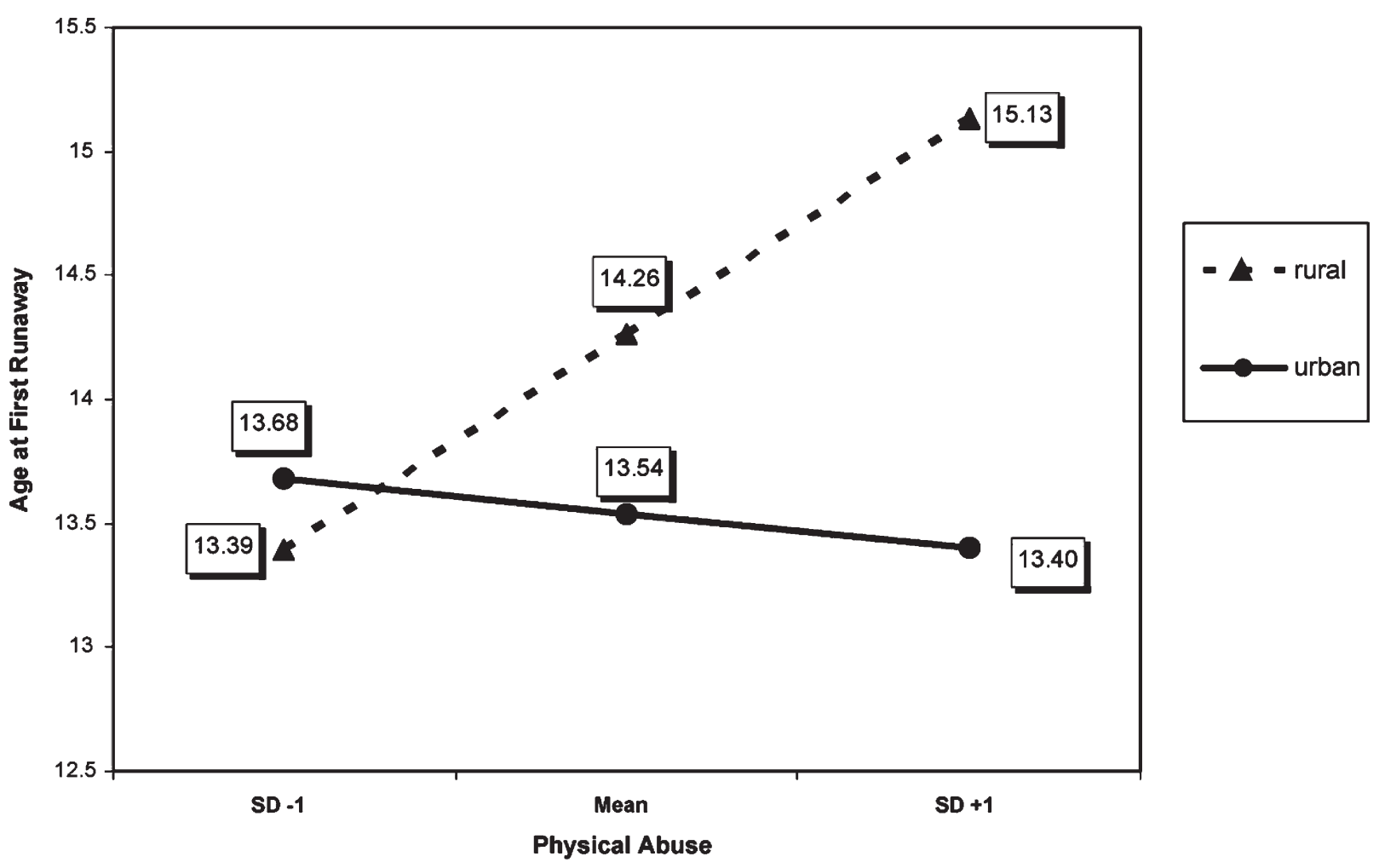

Figure 1. Interaction of physical abuse and community size for age at first runaway for model 1.

effect on how adolescents acquired money, food, or shelter while on the street. It was predicted that childhood abuse and neglect would be positively associated with deviant survival strategies, but this did not prove to be the case (Hypothesis 3).

There were two significant interactions in the model. For urban youth, survival strategies were stable regardless of age at first runaway. However, rural adolescents who ran away at younger ages relied on higher levels of deviance than did their similarly situated urban counterparts $(\beta=-.77)$. Consistent with our Hypothesis 4, the interaction of physical abuse and community size of first runaway also played a role in the use of deviant subsistence strategies $(\beta=.15)$. At higher levels of physical abuse, rural youth reported higher levels of deviant subsistence strategies than urban adolescents, whose rates remained fairly stable across levels of physical abuse. The final model explained $11 \%$ of the variation in deviant survival strategies.

\section{Model 3}

Model 3 investigated the effects of family and street variables on street victimization (Table 2). Those who were neglected $(\beta=.13)$ and who were sexually abused $(\beta=.13)$ experienced higher levels of street victimization. Gender, physical abuse, and age at first runaway were not statistically significant predictors. The findings in regard to sexual abuse and neglect were consistent with our fifth hypothesis; however, physical abuse did not support the predicted association. As family geographic change decreased $(\beta=-.10)$ and change in family structure increased $(\beta=.08)$, street victimization in- 
creased. The direction of the residential mobility construct is unexpected. This may be due to the fact that neighborhood disadvantage and parental income were not controlled for in this study (Crowder \& Teachman, 2004). Supportive of our Hypothesis 6, adolescents' reliance on deviant subsistence strategies increased the rate of street victimization $(\beta=.49)$. No interaction effects were found to be significant. The final model explained $30 \%$ of the variation in street victimization.

\section{Discussion}

We found that dysfunctional family lives were a precursor to early independence and victimization on the street. Our analyses indicated that there were no base differences in age of running away, involvement in deviant subsistence strategies, or rate of street victimization between rural and urban runaways. However, rural adolescents delayed running in the face of abuse and navigated their lives on the street differently. Runaway adolescents report extensive histories of familial physical and sexual abuse. Neglect and sexual abuse decreased the age at first runaway (Hypothesis 1). Consistent with previous research, destructive familial relations were an important predictor of running away (Tyler et al., 2001; Whitbeck \& Hoyt, 1999).

Although studies of homeless and runaway adolescents have not fully explored the ramifications of community size, researchers have become increasingly interested in how community context exposes young people to risk. For instance, there is evidence that community characteristics play a role in child welfare agencies' ability to meet the needs of vulnerable youth (Landsman, 2002; Weissman, Jogerst, \& Dawson, 2003). At a higher frequency of physical abuse (1 standard deviation above the mean), rural adolescents delayed their first runaway by nearly a year and a half compared to urban youth (Hypothesis 2). This may suggest that rural environments offer fewer options for adolescents trapped in abusive familial relationships because rural areas lack shelters and other needed social services to assist them.

Contrary to our expectations, neglect and abuse did not predict the use of deviant survival strategies (Hypothesis 3) as previous studies have found (Hagan \& McCarthy, 1997; Whitbeck \& Hoyt, 1999). We reasoned that having been subjected to higher rates of abusive and/or neglectful families would promote aggressive tendencies and make youth shrewder in their calculation of rewards to costs. Therefore, we anticipated that these maladaptive family relations would orientate youth to satisfying their immediate needs on the street (e.g., food, shelter) rather than taking into account the risks and long-term consequences associated with theft, drug sales, or prostitution.

We found partial support for Hypothesis 4 because in the context of physical abuse, deviant subsistence strategies differed markedly for rural and urban adolescents. Physical abuse had little bearing on urban adolescents' survival via the street economy, but rural youth were more embedded in street subsistence when they reported a higher incidence of physical abuse. The authors suggest that informal personal ties in rural communities are an important buffer for young people that consider running away; we posit that these personal networks effectively avert some instances of run away behavior. However, these benefits do not apply to all youth. Formal and informal community structures are obviously not working for our sample of rural runaways, or they would not be running away to larger cities. A higher frequency of abuse could eliminate legitimate social networks for rural youth more effectively than for urban runaways, thus making the street economy their only means of survival. Having been subjected to abusive family over a longer period of time, rural runaways may be more damaged as a result and have smaller social networks to rely on for instrumental financial support, which could increase their reliance on deviant subsistence strategies. 
In regard to the second interaction, deviant subsistence was fairly stable for urban youth regardless of the age at first running away. This was not so for rural adolescents. In fact, younger rural adolescents were more dependent on deviant subsistence strategies. One possible explanation is that daily survival necessitates the use of the street economy because they do not have a social network in place that could provide needed support. At the same time, younger rural adolescents would have less experience gaining access to social service agencies geared to their needs. In addition, due to their age, younger adolescents would have fewer options for legitimate work (e.g., day labor). This could account for some of the differences observed because shelters and drop-in centers, employment, and social networks provide much needed resources that reduce runaways' reliance on deviant subsistence strategies.

The final hazard for runaways in our study was street victimization. Consistent with previous research, dysfunctional familial relations were linked to exploitation on the street (Janus et al., 1995; Whitbeck \& Hoyt, 1999). After controlling for other risk factors, the trauma of childhood abuse or neglect increased the odds of street victimization by nearly three times in a study of homeless adults (Lee \& Schreck, 2005). Supporting our fifth hypothesis, neglect and sexual abuse increased the level of street victimization. Other studies have suggested that the impact of abuse on street victimization is indirect through high-risk behaviors associated with being abused (e.g., deviant peers and deviant subsistence strategies) (Whitbeck \& Simons, 1990). This would be a potential explanation for the absence of a main effect of physical abuse on street victimization (Hypothesis 5).

Runaways report a high level of deviant activity. These high-risk behaviors increase their vulnerability to becoming victims themselves (Baron, 2003; Hagan \& McCarthy, 1997; Kipke et al., 1997; Whitbeck \& Simons, 1990). Our findings found strong support for the linkage between deviant subsistence strategies and street victimization (Hypothesis 6).

There were four limitations of this study. They include self-report data, cross-sectional data, absence of community level variables, and the sampling technique. The adolescent was the sole source of information about her/his experiences. We relied on cross-sectional data, which cannot directly evaluate effects over time. We did not have community level variables such as funding for social welfare programs and community involvement and attachment to examine how they influence runaway behavior. Within the urban category, the city size measure included communities that may offer different levels of resources. Due to the small sample of rural youth, alternate classifications to define rural versus urban were conducted, but none showed significant contrasts. Agencies serving these youth are naturally under time constraints that reinforced a selection bias. The majority of the adolescents in this sample were shelter youth, although they were not immune to living on streets.

Despite these limitations, we believe this study makes an important contribution to the research on homeless and runaway youth. This analysis considered the role that community size and family characteristics played in the lives of runaway adolescents. At a higher level of physical abuse, rural youth remained in their families longer and employed deviant subsistence strategies to a greater extent than similarly situated urban runaways. For abused rural youth, engaging in street deviance may put them at higher risk of victimization by street predators and encounters with the justice system.

Acknowledgments - The Midwest Homeless and Runaway Adolescent Project is supported by the National Institute of Mental Health (MH501140); Principal Investigator, Les B. Whitbeck. This article is Journal Paper J-17329 of the Iowa Agriculture and Home Economics Experiment Station, Ames, Iowa, Project 3320. The authors thank anonymous reviewers and the editor for their helpful comments. 


\section{References}

Baron, S. (2003). Street youth violence and victimization. Trauma Violence and Abuse, 4(1), 22-44.

Committee on Labor and Human Resources. (1990). Examining the impact of homelessness and dislocation on young people in America. Washington, DC: U.S. Government Printing Office.

Crowder, K., and Teachman, J. (2004). Do residential conditions explain the relationship between living arrangements and adolescent behavior? Journal of Marriage and Family, 66, 721-738.

Drabenstott, M., and Gibson, L. (1988). In M. Drabenstott, and L. Gibson (Eds.), Rural America in transition. Kansas City, MO: The Federal Reserve Bank of Kansas City.

Finkelhor, D., Hotaling, G., and Sedlak, A. (1990). Missing, abducted, runaway, and throwaway children in America. Washington, DC: Office of Juvenile Justice and Delinquency Prevention.

Hagan, J., and McCarthy, B. (1997). Mean streets: Youth crime and homelessness. New York: Cambridge University Press.

Hammer, H., Finkelhor, D., and Sedlak, A. J. (2002). Runaway/thrownaway children: National estimates and characteristics. Washington, DC: Office of Juvenile Justice and Delinquency Prevention.

Herrera, V., and McCloskey, L. (2001). Gender differences in the risk for delinquency among youth exposed to family violence. Child Abuse and Neglect, 25, 1037-1051.

Hoyt, D., Conger, R., Gaffney Valde, J., and Weihs, K. (1997). Psychological distress and help seeking in rural America. American Journal of Community Psychology, 25, 449-470.

Hoyt, D., Ryan, K., and Cauce, A. (1999). Personal victimization in a high-risk environment: Homeless and runaway adolescents. Journal of Research in Crime and Delinquency, 36(4), 371-392.

Janus, M., Archambault, F., Brown, S., and Welsh, L. (1995). Physical abuse in Canadian runaway adolescents. Child Abuse and Neglect, 19(4), 433-447.

Janus, M., Burgess, A., and McCormack, A. (1987). Adolescent runaways: Causes and consequences. Lexington, MA: Lexington Books.

Johnson, S., Bowers, K., and Hirschfield, A. (1997). New insights into the spatial and temporal distribution of repeat victimization. British Journal of Criminology, 37, 224-241.

Kaufman, J., and Spatz Widom, C. (1999). Childhood victimization, running away, and delinquency. Journal of Research in Crime and Delinquency, 36(4), 347-370.

Kipke, M., Simon, T., Montgomery, S., Unger, J., and Iverson, E. (1997). Homeless youth and their exposure to and involvement in violence while living on the streets. Journal of Adolescent Health, 20, 360-367.

Kufeldt, K., and Nimmo, M. (1987). Youth on the street: Abuse and neglect in the eighties. Child Abuse and Neglect, 11, 531-543.

Landsman, M. (2002). Rural child welfare practice from an organization-in-environment perspective. Child Welfare League of America, 791-819.

Lauritsen, J., Sampson, R., and Laub, J. (1991). The link between offending and victimization among adolescents. Criminology, 29, 265-291.

Lee, B., and Schreck, C. (2005). Danger on the streets: Marginality and victimization among homeless people. American Behavioral Scientist, 48(8), 1055-1081.

Maxfield, M., and Spatz Widom, C. (1996). The cycle of violence. Archives of Pediatrics and Adolescent Medicine, 150, 390-395.

McCormack, A., Janus, M., and Burgess, A. (1986). Runaway youths and sexual victimization: Gender differences in an adolescent runaway population. Child Abuse and Neglect, 10, 387-395.

Nye, F. (1979). Choice, exchange, and the family. In W. Burr, R. Hill, F. Nye, and I. Reiss (Eds.), Contemporary theories about the family: Vol. 2, (pp. 1-41). New York: Free Press. 
Nye, F. (1980). A theoretical perspective on running away. Journal of Family Issues, 1(2), 274-299.

Powers, J., Eckenrode, J., and Jaklitsch, B. (1990). Maltreatment among runaway and homeless youth. Child Abuse and Neglect, 14, 87-98.

Simons, R., and Whitbeck, L. (1991). Sexual abuse as a precursor to prostitution and victimization among adolescent and adult homeless women. Journal of Family Issues, 12, 361-379.

Stiffman, A. (1989). Physical and sexual abuse in runaway youths. Child Abuse and Neglect, 13, 417-426.

Straus, M., and Gelles, R. (1990). Physical violence in American families. Brunswick, NJ: Transaction.

Tyler, K., Hoyt, D., Whitbeck, L., and Cauce, A. (2001). The impact of childhood sexual abuse on later sexual victimization among runaway youth. Journal of Research on Adolescence, 11(2), 151-176.

Weissman, A., Jogerst, G., and Dawson, J. (2003). Community characteristics associated with child abuse in Iowa. Child Abuse and Neglect, 27, 1145-1159.

Whitbeck, L., and Hoyt, D. (1999). No where to grow: Homeless and runaway adolescents and their families. New York: Aldine de Gruyter.

Whitbeck, L., Hoyt, D., and Ackley, K. (1997). Families of homeless and runaway adolescents: A comparison of parent/caretaker and adolescent perspectives on parenting, family violence, and adolescent conduct. Child Abuse and Neglect, 21(6), 517-528.

Whitbeck, L., and Simons, R. (1990). Life on the streets: The victimization of runaway and homeless adolescents. Youth and Society, 22(1), 108-125.

Zingraff, M., Leiter, J., Myers, K., and Johnson, M. (1993). Child maltreatment and youthful problem behavior. Criminology, 31, 173-202. 